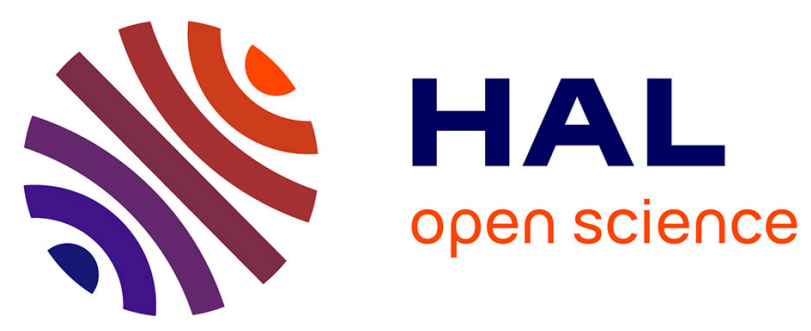

\title{
Search for factors involved in the rapid shift in watermelon mosaic virus (WMV) populations in south-eastern France
}

Hervé Lecoq, Frederic Fabre, Benoit Joannon, Catherine Wipf-Scheibel, Charlotte Chandeysson, Alexandra Schoeny, Cecile Desbiez

\section{To cite this version:}

Hervé Lecoq, Frederic Fabre, Benoit Joannon, Catherine Wipf-Scheibel, Charlotte Chandeysson, et al.. Search for factors involved in the rapid shift in watermelon mosaic virus (WMV) populations in south-eastern France. Virus Research, 2011, 159 (2), pp.115-123. 10.1016/j.virusres.2011.05.004 . hal-02652326

\section{HAL Id: hal-02652326 \\ https://hal.inrae.fr/hal-02652326}

Submitted on 29 May 2020

HAL is a multi-disciplinary open access archive for the deposit and dissemination of scientific research documents, whether they are published or not. The documents may come from teaching and research institutions in France or abroad, or from public or private research centers.
L'archive ouverte pluridisciplinaire HAL, est destinée au dépôt et à la diffusion de documents scientifiques de niveau recherche, publiés ou non, émanant des établissements d'enseignement et de recherche français ou étrangers, des laboratoires publics ou privés.

\section{다(1)(2)}

Distributed under a Creative Commons Attribution - ShareAlikel 4.0 International 
Version définitive du manuscrit publié dans / Final version of the manuscript published in : Virus Research, 2011, In press, DOI:10.1016/j.virusres.2011.05.004. The original publication is available at http://www.sciencedirect.com/science/article/pii/S0168170211001717

Search for factors involved in the rapid shift in Watermelon mosaic virus (WMV) populations in South-eastern France

\author{
H. Lecoq*, F. Fabre, B. Joannon, C. Wipf-Scheibel, C. Chandeysson, A. Schoeny, C. Desbiez \\ INRA, UR407, Station de Pathologie Végétale, Domaine Saint Maurice, 84140 Montfavet, France.
}

*Corresponding author. Tel.: +33 4327228 56; fax: +33 432722842.

E-mail address: Herve.Lecoq@avignon.inra.fr

\begin{abstract}
Watermelon mosaic virus (WMV, genus Potyvirus, family Potyviridae) was reported for the first time in France in 1974, and it is now the most prevalent virus in cucurbit crops. In 2000, new strains referred as 'emerging' (EM) strains were detected in South-eastern France. EM strains are generally more severe and phylogenetically distinct from those previously reported in this country and referred as 'classic' (CL) strains. Since 2000, EM strains have been progressively replacing CL strains in several areas where they co-exist. In order to explain this rapid shift in virus populations, the biological properties of a set of $17 \mathrm{CL}$ and EM WMV isolates were compared. No major differences were observed when comparing a limited host range including 48 different plant species or cultivars. Only two species were differential; Chenopodium quinoa was systemically infected by CL and not by EM isolates whereas Ranunculus sardous was systemically infected by EM and not by CL isolates. A considerable variability was observed in aphid transmission efficiencies but this could not be correlated to the CL or EM types. Two subsets of five isolates of each group were used to compare aphid transmission efficiencies from single and double (CL-EM) infections using six different cucurbit and non-cucurbit hosts. EM isolates were generally better transmitted from mixed CL-EM infections than CL isolates and CL transmission rates were significantly lower from double than from single infections. Cross-protection was only partial between CL and EM strains leading to frequent double infections, and only a slight asymmetry was observed in cross-protection efficiencies. Since double infections occur very commonly in fields, the preferential transmission of EM from mixed CL-EM infections could be one of the factors leading to the displacement of CL isolates by EM isolates.
\end{abstract}

\author{
Keywords: \\ Emergence \\ Cross-protection \\ Host range \\ Aphid transmission \\ Mixed infection
}


Version définitive du manuscrit publié dans / Final version of the manuscript published in : Virus Research, 2011, In press, DOI:10.1016/j.virusres.2011.05.004. The original publication is available at http://www.sciencedirect.com/science/article/pii/S0168170211001717

\section{Introduction}

Watermelon mosaic virus (WMV, genus Potyvirus, family Potyviridae) is one of the major viruses infecting cucurbit crops in countries with temperate or Mediterranean climates world wide (Lecoq and Desbiez, 2008). WMV can also cause severe diseases in legumes (pea, bean) and orchids (vanilla) and it infects several weeds (including shepherd's purse, Capsella bursa-pastoris) that can be virus reservoirs in the absence of susceptible crops (Lecoq, 1992, Lecoq and Desbiez, 2008). In France, WMV was first isolated in 1974 from melon (Luis Arteaga et al., 1976) and it has since been reported to cause regular epidemics, with severe symptoms of mosaic, vein banding, leaf deformations and fruit discoloration in melon, but only mild mottle symptoms of little economic importance in zucchini squash (Lecoq, 1992, Desbiez et al., 2007). Since 2000, unusually severe WMV symptoms have been reported in zucchini squash including severe mosaic and distortion on leaves and fruits (Desbiez et al., 2007). The characterization of different WMV isolates based on partial coat protein sequences indicated that most isolates collected in France before 1999 belonged to Phylogenetic group 1 (otherwise named 'classic', CL), while the more severe WMV isolated in 2000 and subsequently belonged to the distinct Phylogenetic group 3 (otherwise named 'emerging', EM) (Desbiez et al., 2007, 2009).

EM isolates are closely related to WMV isolates from the Far East and are distributed in four distinct phylogenetic sub-groups (EM1 to EM4) presenting a strong geographical structure in South-eastern France (Desbiez et al., 2007, Joannon et al., 2010). EM WMV isolates may have been introduced from Asia, although a putative introduction route has not yet been identified. WMV has not been reported to be seed-borne, but it might have been introduced, either through infected fruits (Lecoq et al., 2003) or infected plant material, including susceptible ornamental hosts.

A major feature of WMV in South-eastern France during the last decade has been a very rapid shift in virus populations. EM isolates are becoming more prevalent and have replaced CL isolates almost completely in some areas (Desbiez et al., 2009). The reasons for this important change are not yet known. Identifying the ecological and evolutionary factors driving this process would be a first step towards predicting which viruses are most likely to become successful invaders.

Fitness may be defined as the relative reproductive ability in a defined environment and for a plant virus it depends on within-host multiplication, transmission efficiency between hosts or host range size (Roossinck, 1997). This paper reports experiments intended to compare different features that could reflect differences in fitness between CL and EM isolates, including a comparison of their host ranges and aphid transmission efficiencies. Since CL-EM mixed infections are very frequent in the field (Desbiez et al., 2009; Fabre et al., 2010), aphid transmission efficiencies from plants with single or double infections were also compared. Finally, the cross-protection efficiencies between CL and EM WMV isolates were studied in controlled conditions.

\section{Materials and methods}

\subsection{Virus isolates}

Seventeen WMV isolates, belonging to Phylogenetic group 1 ('classic', CL) and group 3 ('emerging', EM) (Desbiez et al., 2007, 2009), representing the virus molecular diversity observed in South-Eastern France, were used in this study. Their geographical origin and year of isolation are presented in Table 1 and their phylogenetic relationships in Fig. 1. These isolates were first checked by DAS-ELISA to ensure the absence of any other cucurbit-infecting viruses. Ten isolates were passed through single local lesion transfers on Chenopodium amaranticolor and C. quinoa while the others were checked for purity by the absence of double peaks after direct sequencing of RTPCR products corresponding to the N-terminal part of the P1, cylindrical inclusion and coat protein coding regions (Table 1 and data not shown). 


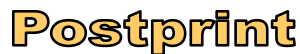

Version définitive du manuscrit publié dans / Final version of the manuscript published in : Virus Research, 2011, In press, DOI:10.1016/j.virusres.2011.05.004. The original publication is available at http://www.sciencedirect.com/science/article/pii/S0168170211001717

\subsection{ELISA tests}

The presence of WMV in test plants was checked by double-antibody sandwich enzymelinked immunosorbent assay (DAS-ELISA) using purified immunoglobulins G (IgGs) and alkaline phosphatase conjugated IgGs from a WMV-specific polyclonal antiserum produced in our laboratory against WMV-FR. Triple-antibody sandwich (TAS)-ELISA tests were conducted according to Desbiez et al. (2007) using monoclonal antibodies (Mabs) EG2 which detects all WMV isolates tested so far and EB11 which detects CL isolates specifically. An additional Mab (2C6) was obtained during this study as in Desbiez et al. (2007) using FMF00-LL1 (an EM1 isolate) purified virus preparations as an immunogen; Mab 2C6 thus obtained detects EM isolates specifically and not CL isolates (Table 2). Leaf samples to be tested were ground in the inoculation buffer (see 2.3) at a ratio of 1:10 (wt:vol). One hundred $\mu \mathrm{l}$ of extracts were deposited per well of a microtitration plate, using two wells for each sample. Paranitrophenol $(1 \mathrm{mg} / \mathrm{ml})$ was used as a substrate and absorbance $\left(A_{405}\right)$ was measured after 1 to $3 \mathrm{~h}$ using a Titertek Multiskan RC spectrophotometer (Labsystems, Helsinki, Finland).

\subsection{Mechanical inoculations and host range studies}

Virus isolates were originally kept in samples dried over $\mathrm{CaCl} 2$. Dried samples (and subsequently leaves from infected plants) were triturated with $0.03 \mathrm{M} \mathrm{Na} 2 \mathrm{HPO}_{4}$ containing $0.2 \%$ Na-diethyldithiocarbamate (DIECA) $(1: 10 ; \mathrm{w} / \mathrm{v})$ with a mortar and pestle. Extracted juice was mixed with 400-mesh Carborundum ${ }^{\circledR}(75 \mathrm{mg} / \mathrm{ml})$ and activated charcoal $(75 \mathrm{mg} / \mathrm{ml})$ before being rubinoculated on zucchini squash (Cucurbita pepo) plants kept under cages in insect-proof greenhouses.

The susceptibility of 45 plant species or cultivars belonging to 14 botanical families (Table 3) to seven WMV isolates was tested following mechanical inoculation of groups of two to six plants for each species or cultivar. For three additional species (Vanilla sp) mechanical inoculations were erratic and were replaced by inoculations with ten viruliferous aphids per plant (see 2.4). The seven isolates included three CL isolates (FR, FMF00-LL2 and C05-337) and one from each of the four EM subgroups (FMF00-LL1, FMF03-141, FBR04-37 and C05-270) (Desbiez et al., 2007). The other ten isolates were tested on a subset of 28 species of 13 botanical families. Only systemic infections were checked 4 weeks after inoculation by DAS-ELISA using polyclonal antibodies and TAS-ELISA using EG2 Mab.

\subsection{Aphid transmission experiments}

A clonal Myzus persicae population maintained in the laboratory for more than 30 years on pepper (Capsicum annuum) was used for non-persistent transmission of 17 WMV isolates according to Lecoq et al. (1979). Since these isolates have been maintained in the greenhouse for various periods of time through successive mechanical inoculations and this process may affect aphid transmission efficiencies (Legavre et al., 1996), the 17 isolates were first subjected to three rounds of aphid transmission, before being used as virus sources.

In the first experiments, the transmission rates of the $17 \mathrm{WMV}$ isolates acquired on singly infected plants were compared as follow. To get homogenous apterous adults, 10-15 adult aphids were placed on healthy pepper plants and allowed to produce larvae for 2 days. The adults were then removed and the remaining larvae were used 6-7 days later when they had reached the adult stage (Lecoq et al., 1979). Aviruliferous aphids were starved for 1-2 hr before being allowed a 1-2 min acquisition access period on an infected leaf of a young zucchini squash plant, 3 to 4 weeks after inoculation. Aphids were then deposited one per plant on each of 30 melon (Cucumis melo) test plants for a $2 \mathrm{hr}$ inoculation period. Inoculated plants were sprayed with an aphicide (Confidor ${ }^{\circledR}$, $0.5 \mathrm{ml} / \mathrm{l}$ ) before being transferred to an insect-proof greenhouse. Symptoms were noted three weeks later. The test was repeated six times. The effect of the fixed factors "Virus isolates" (17 levels) and "Phylogenetic group of the isolates" (two levels: CL and EM) on the binomial response variable "Number of plant infected" were tested with one-way generalized linear models. 


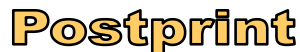

Version définitive du manuscrit publié dans / Final version of the manuscript published in : Virus Research, 2011, In press, DOI:10.1016/j.virusres.2011.05.004. The original publication is available at http://www.sciencedirect.com/science/article/pii/S0168170211001717

A second set of experiments was designed to compare transmission efficiencies of CL and EM isolates acquired from plants with single or double (CL and EM) infections. Similar conditions were used except that transfers were to 15 test plants per source leaf. Moreover, six species of source plants, all susceptible to both CL and EM isolates, were used: zucchini squash, melon, shepherd's purse (C. bursa-pastoris), bean (Phaseolus vulgaris var Black turtle soup 2), Nicotiana clevelandii and Nicotiana benthamiana. Five CL-EM combinations were tested using isolates that were shown to have similar aphid transmission rates in the first set of experiments. Two combinations were with isolates collected in the same field, the same day (MFT03-75/MFT03-91 and C05-464/C05-465). One combination was with isolates collected in the same field but in different years (FR/FMF00-LL1) and two combinations were with isolates collected in different sites from the same area, the same year (C06-526/C06-257) or different years (FMF00-LL2/C06097).

In the first experiments (C06-526/C06-257 and C05-464/C05-465), four different source leaves were used for single infections and 16 different source leaves for double infections, whereas in the second series of experiments (FR/FMF00-LL1, MFT03-75/MFT03-91 and FMF00-LL2/C06097), eight different source leaves were used both for single or double infections.

For transmission experiments using plants infected by only one isolate, transmission rates were estimated by checking the number of plants with symptoms, 3 weeks after inoculation. When source plants were doubly infected by CL and EM isolates, transmission rates of each isolate were deduced from TAS-ELISA experiments on infected test plants using Mabs EG2 which detects all WMV isolates, EB11 which detects CL isolates specifically and 2C6 which detects EM isolates specifically (Table 2).

Three statistical analyses were designed to analyze these data. For all statistical analyses, data from each source leaf were treated as independent observations. The first test addressed the transmission rates from singly infected plants. For each source plant species, we tested whether the probability of transmission of a given WMV isolate depends on the factor "Isolate groups" (two levels, CL and EM) when acquisition occurred on singly infected plants. To do so, a generalized linear model testing the effect of the fixed effect factor "Isolate groups" on the binomial response variable "Number of plants infected" was fitted for each of the 30 combinations tested ("6 species of the source plant" $\mathrm{x}$ " 5 Isolates CL-EM"). The second test addressed the transmission rates from doubly-infected plants. For each source plant species, an exact binomial was used to determine whether the proportion of plants infected only by the CL isolate equals the proportion of plants infected only by the EM isolate when acquisition occurred from doubly-infected plants. Test plants doubly-infected were not considered because, using classical statistical analyses, it is impossible to test if the total proportion of plants infected by the CL isolate (alone and in mixed infection with the EM isolate) equal the total proportion of plants infected by the EM isolate (alone and in mixed infection with the CL isolate). Indeed, these data do not fulfill the requirement of independence since doubly-infected plants are counted in both categories.

Finally, the third test asked whether, for a given source plant species, the probability of transmission of a given WMV isolate is modified if acquisition occurred on doubly-infected plants compared to singly-infected plant. This effect was tested as follows for each of the 30 combinations under study. Doubly-infected plants were taken into account in this last analysis. Let $p_{G}$ be the probabilities that an aphid transmits an isolate of group $\mathrm{G}(G \in\{C L, E M\})$ after acquisition on a singly-infected plant. $p_{G}$ was modelled as $\operatorname{logit}\left(p_{G}\right)=\alpha_{G}$. Let $q_{G}$ be the probabilities that an aphid transmits an isolate of group $\mathrm{G}$ after acquisition on a plant doubly-infected by CL and EM. Then, the probability $\phi=\left(\phi_{1}, \phi_{2}, \phi_{3}, 1-\phi_{1}-\phi_{2}-\phi_{3}\right)$ that a plant is infected by the CL isolate only, by the EM isolate only, by both isolates, or by neither virus, respectively, is such that $\phi_{1}=q_{C L} \cdot\left(1-q_{E M}\right)$, $\phi_{2}=q_{E M} \cdot\left(1-q_{C L}\right)$ and $\phi_{3}=q_{E M} \cdot q_{C L}$. Five alternative models were considered for $q_{G}$. In Model 1, $\operatorname{logit}\left(q_{G}\right)=\operatorname{logit}\left(p_{G}\right)$ meaning that acquisition on a plant doubly-infected by CL and EM isolates has 


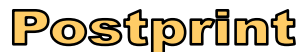

Version définitive du manuscrit publié dans / Final version of the manuscript published in : Virus Research, 2011, In press, DOI:10.1016/j.virusres.2011.05.004. The original publication is available at http://www.sciencedirect.com/science/article/pii/S0168170211001717

no effect on the transmission probabilities (compared to these probabilities when acquisition occurred on singly-infected plant). In Model 2, $\operatorname{logit}\left(q_{G}\right)=\operatorname{logit}\left(p_{G}\right)+\beta$ meaning that acquisition on a doubly-infected plant impacts similarly the transmission probabilities of CL and EM isolates. In Model 3, $\operatorname{logit}\left(q_{G}\right)=\operatorname{logit}\left(p_{G}\right)+\beta_{G}$ meaning that acquisition on a doubly-infected plant impacts differently the transmission probabilities of CL and EM isolates. In Model $4, \operatorname{logit}\left(q_{E M}\right)=\operatorname{logit}\left(p_{E M}\right)+$ $\beta_{E M}$ and $\operatorname{logit}\left(q_{C L}\right)=\operatorname{logit}\left(p_{C L}\right)$ meaning that acquisition on a doubly-infected plant impacts only the transmission probabilities of EM isolates. In Model $5, \operatorname{logit}\left(q_{C L}\right)=\operatorname{logit}\left(p_{C L}\right)+\beta_{C L}$ and $\operatorname{logit}\left(q_{E M}\right)=\operatorname{logit}\left(p_{E M}\right)$ meaning that acquisition on a doubly-infected plant impacts only the transmission probabilities of CL isolates. These five models were fitted using maximum likelihood methods to the dataset assuming that observations in single and double infection experiments are the result of independent binomial $\left(\right.$ Size $=15$, probability $\left.=p_{G}\right)$ and multinomial $(\operatorname{Size}=15$, probability $=\phi$ ) samplings, respectively. Akaike information criteria were used to compare these five models for each of the 30 conditions under study and to identify, for each condition, the model best supported by the data. Finally, when necessary, the sign of the parameters $\beta, \beta_{C L}$ or $\beta_{E M}$ were used to detect whether transmission probabilities were higher (positive sign) or lower (negative sign) when acquisition occurred on mixed-infected plants compared to singly-infected plants. Analyses were coded with the R software environment (http://www.r-project.org/).

\subsection{Cross-protection experiments}

For cross-protection experiments two CL isolates (FMF00-LL2 and C06-526) and four EM isolates (FMF00-LL1, FMF03-141, FBR04-37 and C05-270, one from each EM subgroup) were used to give eight CL/EM combinations. Zucchini squash plants were inoculated at the seedling stage (D0) by the six selected WMV isolates. Groups of five CL-inoculated plants were challenge inoculated on one young leaf by each EM isolate 7 and 14 days (D7 and D14, respectively) after the first inoculation. Similarly, groups of five EM-inoculated plants were challenge inoculated by each CL isolate at D7 and D14. Overall this design defined 16 combinations of WMV isolates (2 "CL isolates" x 4 "EM isolates" x 2 "inoculations status - protecting or challenging isolate") crossed with 2 times of over-infection (D7 and D14) (i.e. time of inoculation of the challenging isolate) (Table 4). Controls included groups of five non-inoculated plants, plants infected by each isolate only at D0, D7 and D14 and plants inoculated with a 1:1 mixture of crude extracts of each CL isolate and each EM isolate at D0. Three replicates of this experiment were performed. The efficiency of cross-protection was checked at least 4 weeks after the challenge inoculation using TAS-ELISA and Mabs EB11 and 2C6 which detect specifically CL and EM isolates, respectively. Statistical analyses were designed to test whether the number of cross-protected plants depends on the effect of two factors ("Group of the challenging isolate" with two levels, CL and EM, and "Time of over-infection" with two levels, D7 and D14) and their interactions. A first generalized linear model testing the effect of three fixed effect factors "Group of the challenging isolate", "Time of over-infection", "Replicate" and their interactions on the binomial response variable "Number of cross-protected plant" revealed highly significant interactions between the two factors of interest and the controlled factor "Replicate". Therefore separate generalized linear model analyses were performed for each replicate. Analyses were also done with the R software environment.

\section{Results}

\subsection{Host range studies}

Among the 48 different plant species or cultivars inoculated by three CL isolates (FR, FMF00-LL2 and C05-337) and four EM isolates (FMF00-LL1, FMF03-141, FBR04-37 and C05270), 27 species or cultivars did not develop systemic infections (Table 3). Although inoculated leaves were not checked by ELISA, some of these hosts (including Lavatera trimestris, Chenopodium amaranticolor, C. murale and Cichorium intybus) developed necrotic or chlorotic local lesions indicative of local infections. Nineteen plant species or cultivars developed systemic 


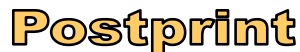

Version définitive du manuscrit publié dans / Final version of the manuscript published in : Virus Research, 2011, In press, DOI:10.1016/j.virusres.2011.05.004. The original publication is available at http://www.sciencedirect.com/science/article/pii/S0168170211001717

infections with the seven isolates (including most cucurbits tested, some pea and bean cultivars, sesame, poppy and vanilla) (Table 3). Symptoms varied greatly according to the isolate and host: severe symptoms were generally observed in cucurbits, sesame, bean, vanilla and Nicotiana benthamiana, while mild or no symptoms were observed in pea, $N$. clevelandii, shepherd's purse or Lamium amplexicaule. Some cultivars of the same species (cucumber, bean and pea) had differential reactions depending on the presence of WMV-resistance genes (Table 3). Similar results were obtained when inoculating the ten other WMV isolates to a subset of 28 species or cultivars belonging to 13 botanical families.

Only one species, $C$. quinoa, was systemically infected by CL isolates but not by EM isolates. In this host EM isolates produced only chlorotic local lesion in inoculated leaves and no symptoms on younger leaves and the virus was not detected by ELISA in the young non-inoculated leaves. In contrast, all CL isolates induced systemic chlorotic spots or mosaic on C. quinoa and the virus was detected by ELISA in the young non-inoculated leaves. Similarly, Ranunculus sardous was the only host tested that was infected systemically by all EM isolates (with no symptoms or mild mosaic) and not systemically infected by any of the CL isolates (Table 3).

Zucchini squash or melon accessions that have intermediate resistance to WMV were all systemically infected by each of the 17 isolates, as the susceptible controls, but they generally developed milder symptoms (data not shown).

\subsection{Comparison of aphid transmission rates}

\subsubsection{Transmission efficiency variation among the WMV (CL-EM) isolates}

An important variability was observed in the aphid transmission efficiencies among the 17 WMV isolates tested. Transmission rates as estimated by the inoculation of a total of 300 melon seedlings by single viruliferous apterous $M$. persicae, varied from $17 \%$ to $70 \%$, with a majority of isolates having transmission rates within the range of $40-60 \%$. The differences observed between isolates could not be related to their phylogenetic group (CL or EM) $(\mathrm{P}$-value $=0.665)($ Fig. 2$)$. The best and least transmitted isolates were EM isolates and, when grouping isolates by increasing transmission rates, the six CL isolates were scattered among the EM isolates (Fig. 2). Overall, the mean transmission rates estimated for CL and EM isolates were similar, $47.7 \%$ and $46.8 \%$, respectively.

\subsubsection{Transmission efficiency variation among virus sources (host, single or double -} infections)

Overall transmission rates from single infections and from the six different hosts were similar, being $39.4 \%$ and $43.4 \%$ for CL or EM isolates, respectively. In the 30 host/virus combinations, CL transmission rates were significantly higher than EM transmission rates 8 times, significantly lower 9 times and no significant differences were observed 13 times (Fig. 3). However, the situation differed according to the hosts: from cucurbit sources CL was better in 6 of 10 combinations, while no significant difference was observed in the 4 other cases. From non-cucurbit sources, EM was better in 9 of 20 combinations, CL better 2 times, and non-significant differences were observed 9 times (Fig. 3).

Overall transmission rates from double-infections and from the six different hosts were more contrasted, being $20.3 \%$ and $36.3 \%$ for CL or EM isolates, respectively. In the 30 host/virus combinations, the proportion of doubly-infected test plants was highly variable, ranging from 0 to $31 \%$. But, among the test plants singly-infected, EM isolates were more frequently transmitted alone than CL isolates 17 times and as often ten times. CL isolates were more frequently transmitted alone than EM isolates only two times (Fig. 3). From cucurbit sources, EM isolates were more frequently transmitted in only two of ten combinations, while no significant differences were observed in the 8 other cases. From non-cucurbit sources, transmission of EM alone was higher in 15 out of 20 combinations, lower 2 times, and not-significantly different 3 times (Fig. 3). 


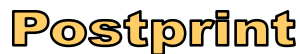

Version définitive du manuscrit publié dans / Final version of the manuscript published in : Virus Research, 2011, In press, DOI:10.1016/j.virusres.2011.05.004. The original publication is available at http://www.sciencedirect.com/science/article/pii/S0168170211001717

Finally, the last statistical analysis tested whether transmission rates are changed when acquisition occurred on CL-EM doubly-infected plants relatively to singly-infected plant. This indicated that EM isolates were generally better transmitted than CL isolates. In $56 \%$ of the cases, EM transmission rates were significantly higher or equal from double than from single infections, whereas at the same time CL transmission rates were significantly lower (in these cases, the model selected by the analysis was either model 5 with $\beta_{C L}<0$ or model 3 with $\beta_{C L}<0$ and $\beta_{E M}>0$ ). The opposite situation (higher or equal CL transmission rates from double than from single infections and lower EM transmission rates) was observed in only 10\% of the cases (model selected: model 4 with $\beta_{E M}<0$ or model 3 with $\beta_{C L}>0$ and $\beta_{E M}<0$ ). Finally, in $34 \%$ of the cases, both CL and EM transmission rates were significantly lower from double than from single infections (model selected: model 2 with $\beta<0$ or model 3 with $\beta_{C L}<0$ and $\beta_{E M}<0$ ). The other possible outcomes of the analysis were not observed among the 30 cases analysed. This trend was observed for cucurbit as well as for non-cucurbit hosts.

\subsection{Cross-protection experiments}

When CL and EM isolates were inoculated concurrently (D0) to the same plants, all plants were doubly-infected (Table 4). When challenge inoculations occurred 7 or 14 days after the first inoculation (D7 and D14, respectively) only a fraction of the plants became doubly-infected, and this proportion decreased with increased time between inoculations (Table 4). No clear picture emerges from these experiments due to substantial variation between replicates. This necessitated separate statistical analyses for each replicate. Replicates 1 and 3 were generally consistent. In particular the probability of efficient cross-protection never depended on the interactions between the factors "Group of the challenging isolate" and "Time of over-infection" (P-values > 0.1), but significantly depended on the "Time of over-infection" (P-value $<10^{-3}$ ). Cross-protection was significantly more efficient when challenge inoculations were made at D14 rather than at D7. The factor "Group of the challenging isolate" was only significant in replicate 3 where cross-protection was more efficient in CL-protected plants (P-value $<10^{-3}$ ). No factor was significant in replicate 2.

\section{Discussion}

Identifying the factors leading to changes in virus population structure is a major challenge for understanding viral emergences and in developing durable control strategies, especially durable virus resistance. Recent studies emphasized the very rapid evolutionary rates of RNA plant viruses (Gibbs et al., 2010). For instance, Zucchini yellow mosaic virus, a potyvirus related to WMV, was estimated to have evolved very rapidly, since it was shown to have a most common ancestor that arose within the range of 119-771 years ago, although it was first identified in the mid-1970s and became epidemic worldwide in the early 1980s (Simmons et al., 2008, Desbiez and Lecoq, 1997). High mutation rates and recombinations are the primary events generating variability within RNA virus population, while genetic drift and selection are important forces driving virus population evolution (Garcia-Arenal et al., 2003). However, another important means of inducing major changes in virus populations affecting cultivated crops is the introduction, often through human activities, of a new virus strain into an environment where indigenous strains already pre-exist. This is claimed to be by far the most important factor influencing the emergence of plant viruses (Anderson et al., 2004).

Several instances of drastic changes in virus populations have been reported in recent years following the introduction of new strains or related virus species, including a persistently aphidtransmitted luteovirus, Barley yellow dwarf virus (Power, 1996; Amaku et al., 2010), a mechanically-transmitted potexvirus, Pepino mosaic virus (PepMV) (Gomez et al., 2009) and whitefly-borne begomoviruses causing tomato yellow leaf curl disease (TYLCD) (Sanchez-Campos et al., 1999; Garcia-Andres et al., 2007; Davino et al., 2006). The situation observed since 2000 for WMV in South-eastern France (Desbiez et al., 2009) is an additional example of what may be called 


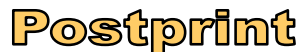

Version définitive du manuscrit publié dans / Final version of the manuscript published in : Virus Research, 2011, In press, DOI:10.1016/j.virusres.2011.05.004. The original publication is available at http://www.sciencedirect.com/science/article/pii/S0168170211001717

'the invasion paradox' (Sax and Brown, 2000, Fabre et al., 2010) where local strains that might be expected to be well adapted to their environment are rapidly displaced by newly introduced ones.

Several parameters may contribute to rapid shifts in virus populations, such as an extended host range that would increase overwintering survival capacities and sources of inoculum or better vector transmission efficiencies that would enhance virus spread. As an example, in the case of TYLCD, Tomato yellow leaf curl virus replaced Tomato yellow leaf curl Sardinia virus within a few years in Southern Spain, probably due to its better transmission by the local biotypes of the vector Bemisia tabaci, and its ability to infect bean (Phaseolus vulgaris), a potential bridge host between tomato crops (Sanchez-Campos et al., 1999).

No major differences were observed in host range between CL and EM WMV isolates and they induced similar reactions in 46 of 48 hosts tested. In particular, several common weeds that were found to be infected by WMV in fall or in winter (Lecoq, 1992) and that could act as virus reservoirs in the absence of cucurbit crops (C. bursa-pastoris, Senecio vulgaris, Lamium amplexicaule) were susceptible to both CL and EM. Only two hosts had differential reactions: $C$. quinoa was systemically infected by CL isolates but not by EM isolates, whereas $R$. sardous was systemically infected by EM isolates but not by CL isolates. These slight differences in host range do not support the hypothesis that EM isolates have a significantly broader host range than CL isolates, although more WMV potential hosts should be tested to reach a definitive conclusion. Indeed, in their comprehensive literature survey Edwardson and Christie (1991) listed 178 hosts locally or systemically susceptible to WMV, including 128 non-cucurbit species, many of which grow in the Mediterranean Basin.

Transmission rates by single $M$. persicae ranged from 17\% (for EM isolate FMF00-LL1) to 70\% (for CL isolate C05-464 and EM isolate C05-465) indicating a high variability between isolates. Although significant differences in transmission rates were observed between isolates, these differences were not correlated to the type of isolate, and the mean transmission rates estimated for CL and EM isolates were very similar. An important variability in transmission frequencies (3\%-84\%) with a continuous distribution was also observed among isolates of Papaya ringspot virus, another potyvirus infecting cucurbits, using the same aphid clone (Quiot-Douine et al., 1990). In a more recent study, no significant differences were observed in the average transmission efficiencies of six Potato virus $Y$ (PVY) isolates by Mp2 $M$. persicae biotype, but differences could be observed when using other $M$. persicae biotypes or other aphid species (Verbeek et al., 2010). Estimating accurately potyvirus aphid transmission efficiencies remains a difficult task (Labonne et al., 1992) and our data are still fragmentary. Indeed, WMV is known to be transmitted by more than 35 aphid species (Lecoq and Desbiez, 2008) and it cannot be excluded that EM isolates could be better transmitted by another aphid vector prevalent in cucurbit crops (Labonne et al., 1982). However, as such, our data do not provide evidence that differences in aphid transmission efficiencies from single infections could be the main driver of the shift in WMV populations observed in South-eastern France.

The frequent occurrence of CL-EM double infections in natural conditions (Desbiez et al., 2009, Fabre et al., 2010) raised the question of a possible role of incomplete cross-protection in the observed shift in WMV populations. Indeed, in instances where a shift in virus populations has been observed such as for TYLCD or PepMV, the minor component of the population was often found mostly in mixed infections indicating an important ecological role for this status (Sanchez-Campos et al., 1999; Davino et al., 2002; Gomez et al., 2009). Recently, Fabre et al. (2010) modeled the codynamics of CL and EM isolates in zucchini squash fields with regard to several epidemiological mechanisms (primary and secondary infection and a wide range of host-virus interactions in coinfected host). Their results first indicated that cross-protection was only partial between CL and EM isolates and secondly that it was more than three times less probable for a CL strain to overinfect more than one week later an EM-infected plant than for an EM strain to over-infect a CLinfected plant. Our experiments confirmed that cross-protection is only partially efficient between 


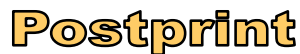

Version définitive du manuscrit publié dans / Final version of the manuscript published in : Virus Research, 2011, In press, DOI:10.1016/j.virusres.2011.05.004. The original publication is available at http://www.sciencedirect.com/science/article/pii/S0168170211001717

CL and EM isolates but the possibility of asymmetrical efficiency remains unclear. This situation was only detected in one of three replicates and in favour of CL isolates. This latter discrepancy between model inferences and our experimental results could be related to several factors. Firstly, our tests were conducted at the seedling stage during fall while the modeling was based on field observations in late spring where plants were at the flowering or fruit setting stages. Secondly, challenge inoculations were done mechanically, while in the field inoculations were done by aphids. It has been shown that individual aphids need to inoculate only very few potyvirus particles to initiate infection (Moury et al., 2007). Differences in cross-protection efficiencies have already been reported between laboratory and field conditions, probably due to differences in physiological conditions or in concentration of the challenge virus (Gal-On and Shiboleth, 2006). Further experiments should be conducted on larger sample size with older plants and using aphid, rather than mechanical, inoculations to investigate this point. Indeed, asymmetrical cross-protection could be a major process influencing viral emergence (Fabre et al., 2010).

The frequent CL-EM mixed infections observed in cultivated crops as well as in weeds (C. Desbiez and H. Lecoq, unpublished) also raised the question of possible differences in virus accumulation of the two types of isolates when in double infection in different hosts. Indeed, mixed infections have been reported to modify important viral traits such as vector transmission rates or virus multiplication, and the fitness of each virus or strain not only depends on its adaptation to the host, but also on its interactions with its co-infection partner (Martin and Elena, 2009). This point was investigated by comparing the aphid transmission efficiencies of five different CL-EM isolate combinations in six different cucurbit or non-cucurbit hosts. A high variability was observed in transmission rates from single infections, but the overall transmission rates of CL and EM isolates from these different hosts were similar. In contrast EM was generally better transmitted than CL from double infections and CL transmission was generally less efficient from double than from single infection. Similarly, the modeling approach of Fabre et al. (2010) derived that CL-EM mixed infected plants slightly favour the spread of EM isolates. These results suggest a competition between CL and EM in mixed infections, in favour of EM, probably because it has a better fitness in mixed infections. This is significant since CL-EM mixed infections are very frequent in fields few weeks after planting (Fabre et al., 2010; C. Desbiez and H. Lecoq, unpublished). Under these conditions, EM isolates have a better dissemination potential to other crops and also to overwintering reservoirs. The effect of this process on viral emergence will be studied using the exploratory model describing WMV epidemiology over several years in a landscape composed of reservoir and cultivated compartments (Fabre et al., 2010). This may allow estimates to be made of the long-term impact of this newly identified parameter in the relative prevalence and distribution of EM and CL isolates of WMV in the environment.

\section{Acknowledgements}

The authors thank the editors for their helpful comments and are grateful to Dr Michel Grisoni and Jean-Pierre Gay (CIRAD, La Réunion) for providing cuttings of Vanilla spp., to Patrick Gognalons for his help in aphid rearing and to Joël Béraud, Michelle Leplat, Laurent Paradis, Michel Pascal and Nathalie Truglio for producing and tending the nearly 20.000 plants used in this study. The Région Provence Alpes Côte d’Azur provided a financial support to Benoît Joannon. 
Version définitive du manuscrit publié dans / Final version of the manuscript published in : Virus Research, 2011, In press, DOI:10.1016/j.virusres.2011.05.004. The original publication is available at http://www.sciencedirect.com/science/article/pii/S0168170211001717

\section{References}

Amaku, M., Burattini, M.N., Countinho, F.A.B., Massad, E., 2010. Modeling the competition between viruses in a complex plant-pathogen system. Phytopathology 100, 1042-1047.

Anderson, P.K., Cunningham, A.A., Patel, N.G., Morales, F.J., Epstein, P.R., Daszak, P., 2004. Emerging infectious diseases of plants: pathogen pollution, climate change and agrotechnology drivers. Trends in Ecol. and Evol., 19, 535-544.

Davino, S., Napoli, C., Davino, M., Accotto, G.P., 2006. Spread of Tomato yellow leaf curl virus in Sicily: partial displacement of another geminivirus originally present. Eur. J. Plant Pathol. 114, 293-299.

Desbiez, C., Costa, C., Wipf-Scheibel, C., Girard, M., Lecoq, H., 2007. Serological and molecular variability of watermelon mosaic virus (genus Potyvirus). Arch. Virol. 152, 775-781.

Desbiez, C., Joannon, B., Wipf-Scheibel, C., Chandeysson, C., Lecoq, H., 2009. Emergence of new strains of Watermelon mosaic virus in South-Eastern France: evidence for limited spread but rapid local population shift. Virus Res. 141, 201-208.

Desbiez, C., Lecoq, H., 1997. Zucchini yellow mosaic virus. Plant Pathol. 46, 809-829.

Edwardson, J.R., Christie, R.G., 1991. The Potyvirus Group. Monograph 16, AES-IFAS, University of Florida, Gainesville.

Fabre, F., Chadœuf, J., Costa, C., Lecoq, H., Desbiez, C., 2010. Asymmetrical over-infection as a process of plant virus emergence. J. Theor. Biol. 265, 377-388.

Gal-On, A., Shiboleth, Y.M., 2006. Cross-protection. In: Loebenstein, G., Carr, J.P. (Eds), Natural resistance mechanisms of plants to viruses. Springer, Dordrecht, pp. 261-288.

Garcia-Andres, S., Accotto, G.P., Navas-Castillo, J., Moriones, E., 2007. Founder effect, plant host, and recombination shape the emergent population of begomoviruses that cause the tomato yellow leaf curl disease in the Mediterranean basin. Virology 359, 302-312.

Garcia-Arenal, F., Fraile, A., 2003. Variation and evolution of plant virus populations. Int. Microbiol. 6, 225-232.

Gibbs, A.J., Fargette, D., Garcia-Arenal, F., Gibbs, M.J. (2010) Time - the emerging dimension of plant virus studies. J. Gen. Virol. 91, 13-22.

Gomez, P., Sempere, R.N., Elena, S.F., Aranda, M.A., 2009. Mixed infections of pepino mosaic virus strains modulate the evolutionary dynamics of this emergent virus. J. Virol. 83, 1237812387.

Joannon, B., Lavigne, C., Lecoq, H., Desbiez, C., 2010. Barriers to gene flow between emerging populations of Watermelon mosaic virus in Southeastern France. Phytopathology, 100:13731379.

Labonne, G., Lupoli, R., Quiot, J.-B., Yvon, M., 1992. The transmissibility of a potyvirus by an aphid vector: reliability of measurements under controlled conditions. Ann. Appl. Biol. 120, 269-278.

Labonne, G., Quiot, J.-B., Monestiez, P., 1982. Rôle des différentes espèces de pucerons vecteurs dans la dissémination du virus de la mosaïque du concombre au niveau d'une parcelle de melon dans le Sud-Est de la France. Agronomie 2, 797-804.

Lecoq, H., 1992. Les virus des cultures de melon et de courgette de plein champ (II). PHM Revue Horticole 324, 15-25.

Lecoq, H., Desbiez, C., 2008. Watermelon mosaic virus and Zucchini yellow mosaic virus. In: B.W.J. Mahy, Van Regenmortel, M.H.V. (Eds), Encyclopedia of Virology, Vol. 5, Third edition, Elsevier, Oxford, pp. 433-440.

Lecoq, H., Desbiez, C., Wipf-Scheibel, C., Girard, M., 2003. Potential involvement of melon fruit in the long distance dissemination of cucurbit potyviruses. Plant Dis. 87, 955-959.

Legavre, T., Maia, I.G., Casse-Delbard, F., Bernardi, F., Robaglia, C., 1996. Switches in the mode of transmission select for or against a poorly aphid-transmissible strain of potato virus $\mathrm{Y}$ with reduced helper component and virus accumulation. J. Gen. Virol. 77,1343-1347. 
Version définitive du manuscrit publié dans / Final version of the manuscript published in : Virus Research, 2011, In press, DOI:10.1016/j.virusres.2011.05.004. The original publication is available at http://www.sciencedirect.com/science/article/pii/S0168170211001717

Luis Arteaga, M.P., Quiot, J.B., Leroux, J., 1976. Mise en évidence d'une souche de watermelon mosaic virus (WMV2) dans le Sud-Est de la France. Ann. Phytopathol. 8, 347-353.

Martin, S., Elena, S. 2009. Application of game theory to the interaction between plant viruses during mixed infections. J. Gen. Virol. 90, 2815-2820.

Moury, B., Fabre, F., Senoussi, R., 2007. Estimation of the number of particles transmitted by an insect vector. Proc. Natl. Acad. Sci., USA 104, 17891-17896.

Power, A.G., 1996. Competition between viruses in a complex plant pathogen system. Ecology 77, 1004-1010.

Quiot-Douine, L., Lecoq, H., Quiot, J.-B., Pitrat, M., Labonne, G., 1990. Serological and biological variability of virus isolates related to strains of papaya ringspot virus. Phytopathology 80, 256263.

Roossinck, M.J., 1997. Mechanisms of plant virus evolution. Annu. Rev. of Phytopathol. 35, 191209.

Sanchez-Campos, S., Navas-Castillo, J., Camero, R., Soria, C., Diaz, J.A., Moriones, E., 1999. Displacement of tomato yellow leaf curl virus (TYLCV)-Sr by TYLCV-Is in tomato epidemics in Spain. Phytopathology 89, 1038-1043.

Sax, D.F., Brown, J.H., 2000. The paradox of invasion. Global Ecol. \& Biogeogr. 9, 363-371.

Simmons, H.E., Holmes, E.C., Stephenson, A.G., 2008. Rapid evolutionary dynamics of zucchini yellow mosaic virus. J. Gen. Virol. 89, 1081-1085. 


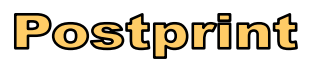

Version définitive du manuscrit publié dans / Final version of the manuscript published in : Virus Research, 2011, In press, DOI:10.1016/j.virusres.2011.05.004. The original publication is available at http://www.sciencedirect.com/science/article/pii/S0168170211001717

Table 1:Year, host and geographical origin of the WMV isolates used in this study.

\begin{tabular}{|c|c|c|c|c|c|c|c|}
\hline \multirow{2}{*}{\multicolumn{2}{|c|}{ Isolate type }} & \multirow{3}{*}{$\begin{array}{l}\text { Isolate name } \\
\text { FR }\end{array}$} & \multirow{2}{*}{\multicolumn{3}{|c|}{ Origin of the isolate }} & \multirow{3}{*}{$\begin{array}{c}\text { GenBank } \\
\text { accession }\end{array}$} & \multirow{3}{*}{$\begin{array}{c}\begin{array}{c}\text { Local } \\
\text { lesion }\end{array} \\
\text { transfer } \\
+^{3} \\
\end{array}$} \\
\hline & & & & & & & \\
\hline \multirow{6}{*}{ 苗 } & \multirow{6}{*}{ CL } & & $\begin{array}{c}\begin{array}{c}\text { Year of } \\
\text { sampling }\end{array} \\
1974 \\
\end{array}$ & $\begin{array}{c}\text { Host } \\
\text { Melon } \\
\end{array}$ & $\begin{array}{c}\text { Location }^{1} \\
\text { Montfavet* }^{*}\end{array}$ & & \\
\hline & & FMF00-LL2 & 2000 & Zucchini & Montfavet* & EU660578 & + \\
\hline & & MFT03-75 & 2003 & Zucchini & Montfavet* & EU660578 2 & \\
\hline & & C05-337 & 2005 & Zucchini & Marmande*** & EU660589 & \\
\hline & & C05-464 & 2005 & Zucchini & Garons** & EU937543 & + \\
\hline & & C06-526 & 2006 & Melon & Bourdic** & EU660578 ${ }^{2}$ & + \\
\hline \multirow{11}{*}{ 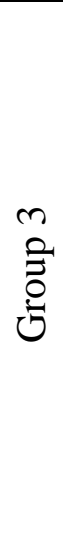 } & \multirow{3}{*}{ EM1 } & FMF00-LL1 & 2000 & Zucchini & Montfavet* & EU660581 & + \\
\hline & & MFT03-91 & 2003 & Zucchini & Montfavet* & EU660581 $^{2}$ & \\
\hline & & C08-427 & 2008 & Zucchini & Montfavet* & EU660581 $^{2}$ & \\
\hline & \multirow{4}{*}{ EM2 } & FMF03-141 & 2003 & Zucchini & Montfavet* & EU660583 & + \\
\hline & & C06-097 & 2006 & Zucchini & Aubignan* & EU6605832 & \\
\hline & & C08-215 & 2008 & Melon & Cadenet* & EU660583 $^{2}$ & \\
\hline & & C08-230 & 2008 & Melon & Pertuis* & EU937555 $^{2}$ & \\
\hline & \multirow{2}{*}{ EM3 } & FBR04-37 & 2004 & Zucchini & Tarascon** & EU660586 & + \\
\hline & & C06-257 & 2006 & Melon & St Chaptes** & EU660586 $^{2}$ & + \\
\hline & \multirow{2}{*}{ EM4 } & C05-270 & 2005 & Melon & Bourdic** & EU660585 & + \\
\hline & & C05-465 & 2005 & Zucchini & Garons** & EU660585 $^{2}$ & + \\
\hline
\end{tabular}

${ }^{1}$ Isolates were mainly from South-eastern France, from the Vaucluse $(*)$ or Gard $(* *)$ 'départements', except one isolate $(* * *)$ originating from South-western France (Tarn et Garonne 'département').

${ }^{2}$ NIb-CP sequence (267-273 bases) identical to the corresponding GenBank accession.

${ }^{3}+$ indicates that the isolate had been subject to single local lesion transfers on Chenopodium amaranticolor and C. quinoa. 


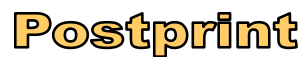

Version définitive du manuscrit publié dans / Final version of the manuscript published in : Virus Research, 2011, In press, DOI:10.1016/j.virusres.2011.05.004. The original publication is available at http://www.sciencedirect.com/science/article/pii/S0168170211001717

\section{Table 2:}

Reactivities of 17 WMV isolates in DAS-ELISA with a polyclonal antiserum and in TAS-ELISA with 3 monoclonal antibodies.

\begin{tabular}{|c|c|c|c|c|c|c|}
\hline \multirow{2}{*}{\multicolumn{2}{|c|}{ Isolate type }} & \multirow{3}{*}{$\begin{array}{l}\text { Isolate name } \\
\text { FR }\end{array}$} & \multirow{3}{*}{$\begin{array}{c}\begin{array}{c}\text { Polyclonal } \\
\text { antiserum }\end{array} \\
\mathbf{2 . 1 3}{ }^{* *}\end{array}$} & \multicolumn{3}{|c|}{ Monoclonal antibodies } \\
\hline & & & & EG2 & EB11 & 2C6 \\
\hline \multirow{6}{*}{ 皇 } & \multirow{6}{*}{ CL } & & & 3.40 & 2.44 & 0.00 \\
\hline & & FMF00-LL2 & 2.03 & 3.37 & 1.77 & 0.00 \\
\hline & & MFT03-75 & 1.90 & 3.18 & 2.17 & 0.01 \\
\hline & & C05-337* & 2.20 & 3.09 & 1.73 & 0.01 \\
\hline & & C05-464 * & 2.75 & 3.24 & 1.53 & 0.01 \\
\hline & & C06-526 & 2.78 & 3.17 & 2.10 & 0.00 \\
\hline \multirow{11}{*}{ 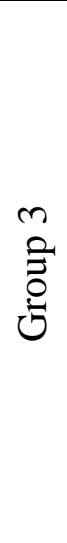 } & \multirow{3}{*}{ EM1 } & FMF00-LL1 & 2.62 & 3.35 & 0.01 & 2.83 \\
\hline & & MFT03-91 & 1.38 & 3.21 & 0.00 & 2.56 \\
\hline & & C08-427* & 1.28 & 3.03 & 0.00 & 0.89 \\
\hline & \multirow{4}{*}{ EM2 } & FMF03-141 & 0.62 & 3.05 & 0.01 & 0.94 \\
\hline & & C06-097 & 1.25 & 3.18 & 0.00 & 2.42 \\
\hline & & C08-215* & 2.04 & 3.26 & 0.00 & 2.55 \\
\hline & & C08-230* & 2.22 & 3.23 & 0.00 & 2.80 \\
\hline & \multirow{2}{*}{ EM3 } & FBR04-37 & 1.15 & 3.26 & 0.00 & 2.13 \\
\hline & & C06-257* & 1.75 & 3.08 & 0.00 & 1.13 \\
\hline & \multirow{2}{*}{ EM4 } & $\mathrm{C} 05-270$ & 0.89 & 3.22 & 0.01 & 1.50 \\
\hline & & C05-465* & 1.15 & 2.89 & 0.00 & 0.79 \\
\hline
\end{tabular}

* Isolates not used for cross-protection experiments or aphid-transmission experiments from CLEM mixed infections were tested in a separate experiment.

** Mean absorbance values at $405 \mathrm{~nm}$ for two wells by isolate, $3 \mathrm{hr}$ after substrate addition. Positive reactions are indicated in bold. 


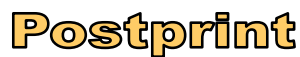

Version définitive du manuscrit publié dans / Final version of the manuscript published in : Virus Research, 2011, In press, DOI:10.1016/j.virusres.2011.05.004. The original publication is available at http://www.sciencedirect.com/science/article/pii/S0168170211001717

\section{Table 3:}

Comparative host range of WMV isolates belonging to phylogenetic groups 1 (CL) or 3 (EM) ${ }^{1}$.

Hosts not systemically infected by CL and EM WMV isolates
Althea rosea, Apium graveolens, Bryonia dioica, Chenopodium amaranticolor, C. murale, Cichorium endivia, Cucumis sativus var Taichung Mou Gua ${ }^{2}$, Datura stramonium, Foeniculum vulgare, Glycine max, Helianthus annuus, Hordeum vulgare, Lavatera trimestris, Medicago sativa, Nicotiana tabacum var Xanthi, Ocimum basilicum, Petrosilenum crispum, Phaseolus vulgaris var Black Turtle Soup 1, Pisum sativum var Douce Provence, Salvia sclarea, Sonchus oleraceus, Sorghum bicolor, Taraxacum officinale, Trifolium incarnatum, Triticum aestivum, Zea mays, Zinnia elegans.
Hosts systemically infected by CL and EM WMV isolates

Capsella bursa-pastoris, Citrullus lanatus, Cucumis melo, Cucumis sativus var Beit Alpha, Cucurbita pepo, Lamium amplexicaule, Nicotiana benthamiana, $N$. clevelandii, Papaver orientale, Phaseolus vulgaris var Black Turtle Soup 2, Pisum sativum var Colmo, Senecio vulgaris, Sesamum indicum, Spinacia oleracea, Torenia fournieri, Valerianella olitoria, Vanilla planifolia, $V$. pompona, $V$. tahitensis.

Host systemically infected by CL $\quad$ Chenopodium quinoa. but not by EM WMV isolates but not by CL WMV isolates

${ }^{1}$ The 28 species or cultivars in bold were inoculated separately by each of the 17 isolates (see Table 1). The 20 other species were inoculated by a representative subset of 10 of these isolates (CL isolates FR, FMF00-LL2 and C05-337 and EM isolates FMF00-LL1, FMF03-141, FBR04-37 and C05-270).

${ }^{2}$ Cultivars names are indicated only when differential reactions were observed between cultivars of a same species. 


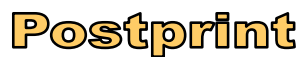

Version définitive du manuscrit publié dans / Final version of the manuscript published in : Virus Research, 2011, In press, DOI:10.1016/j.virusres.2011.05.004. The original publication is available at http://www.sciencedirect.com/science/article/pii/S0168170211001717

Table 4:

Cross-protection efficiency between CL and EM isolates. Challenging isolates were inoculated at the same time as the protecting isolate (D0) or 7 or 14 days later (D7 and D14, respectively).

\begin{tabular}{|c|c|c|c|c|}
\hline \multirow{2}{*}{$\begin{array}{l}\text { Protecting } \\
\text { isolate }\end{array}$} & \multirow{2}{*}{$\begin{array}{c}\text { Challenging } \\
\text { isolate }\end{array}$} & \multicolumn{3}{|c|}{ Time of challenge inoculation } \\
\hline & & D0 & D7 & D14 \\
\hline FMF00-LL2 & FMF00-LL1 ${ }^{1}$ & \multirow{2}{*}{$15 / 15^{2}$} & $10 / 15$ & $8 / 15$ \\
\hline FMF00-LL1 & FMF00-LL2 & & $14 / 15$ & $11 / 15$ \\
\hline FMF00-LL2 & FMF03-141 & \multirow{2}{*}{$15 / 15$} & $5 / 15$ & $2 / 15$ \\
\hline FMF03-141 & FMF00-LL2 & & $10 / 15$ & $6 / 15$ \\
\hline FMF00-LL2 & FBR04-37 & \multirow{2}{*}{$15 / 15$} & $9 / 15$ & $8 / 15$ \\
\hline FBR04-37 & FMF00-LL2 & & $11 / 15$ & $7 / 15$ \\
\hline FMF00-LL2 & $C 05-270$ & \multirow{2}{*}{$15 / 15$} & $9 / 15$ & $6 / 15$ \\
\hline$C 05-270$ & FMF00-LL2 & & $11 / 15$ & $7 / 15$ \\
\hline C06-526 & FMF00-LL1 & \multirow{2}{*}{$15 / 15$} & $12 / 15$ & $5 / 15$ \\
\hline FMF00-LL1 & C06-526 & & $13 / 15$ & $6 / 15$ \\
\hline C06-526 & FMF03-141 & \multirow{2}{*}{$15 / 15$} & $8 / 15$ & $5 / 15$ \\
\hline FMF03-141 & C06-526 & & $11 / 15$ & $3 / 15$ \\
\hline C06-526 & FBR04-37 & \multirow{2}{*}{$15 / 15$} & $8 / 15$ & $7 / 15$ \\
\hline FBR04-37 & C06-526 & & $10 / 15$ & $9 / 15$ \\
\hline C06-526 & C05-270 & \multirow{2}{*}{$15 / 15$} & $9 / 15$ & $4 / 15$ \\
\hline$C 05-270$ & C06-526 & & $10 / 15$ & $8 / 15$ \\
\hline CL-all isolates & EM-all isolates & \multirow{2}{*}{$120 / 120$} & $70 / 120$ & $45 / 120$ \\
\hline EM-all isolates & CL-all isolates & & $90 / 120$ & $57 / 120$ \\
\hline
\end{tabular}

${ }^{1}$ EM isolates are indicated in bold and italics.

${ }^{2}$ Number of plants in which the challenging isolate was detected 4 weeks after challenge inoculation leading to mixed infections, divided by the number of challenged plants. Data correspond to three independent experiments. All control plants inoculated by only one isolate at D0, D7 and D14 were infected (data not shown). 
Version définitive du manuscrit publié dans / Final version of the manuscript published in : Virus Research, 2011, In press, DOI:10.1016/j.virusres.2011.05.004. The original publication is available at http://www.sciencedirect.com/science/article/pii/S0168170211001717
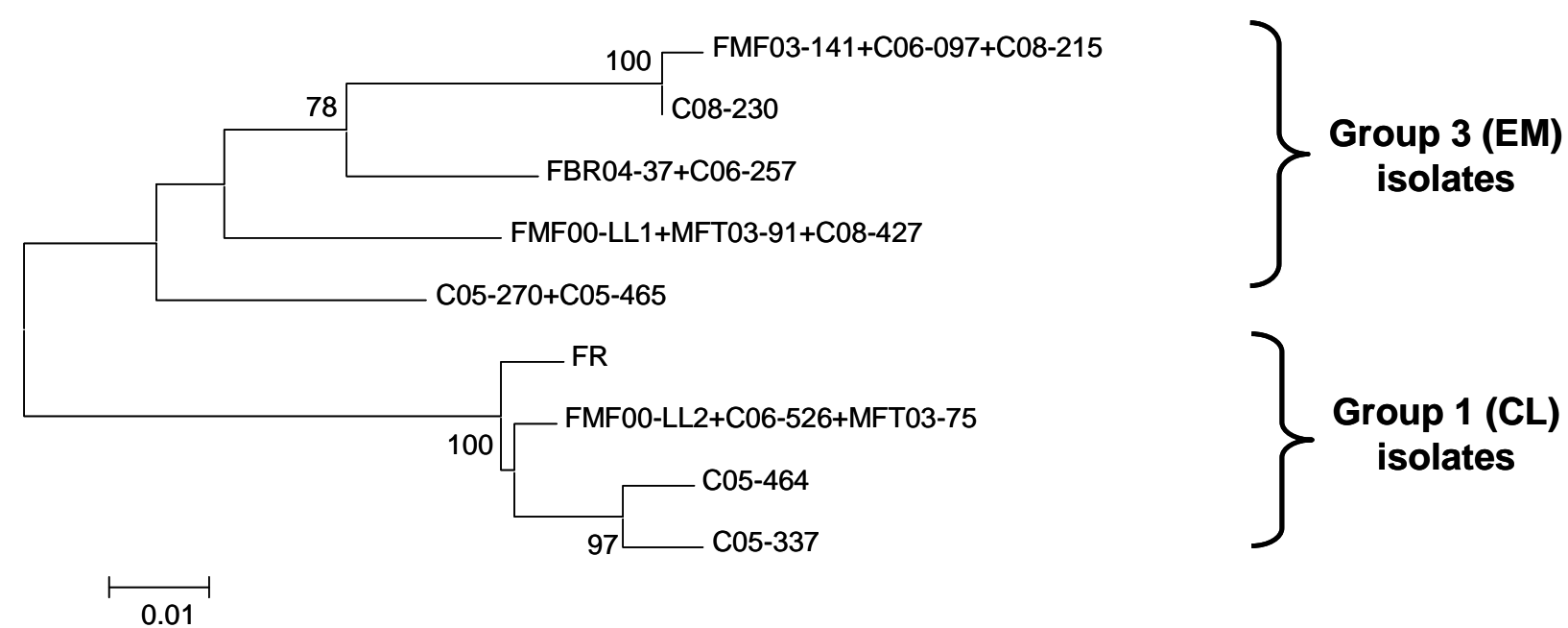

Fig. 1. Distance tree obtained for a 218-224 nucleotide sequence in the coat protein N-terminal region of each of the $17 \mathrm{WMV}$ isolates used in this study. Bootstrap supports (1000 bootstraps) are indicated as percentages for values above $60 \%$. The scale bar represents a genetic distance of 0.01 . 


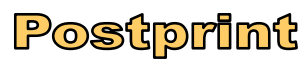

Version définitive du manuscrit publié dans / Final version of the manuscript published in : Virus Research, 2011, In press, DOI:10.1016/j.virusres.2011.05.004. The original publication is available at http://www.sciencedirect.com/science/article/pii/S0168170211001717

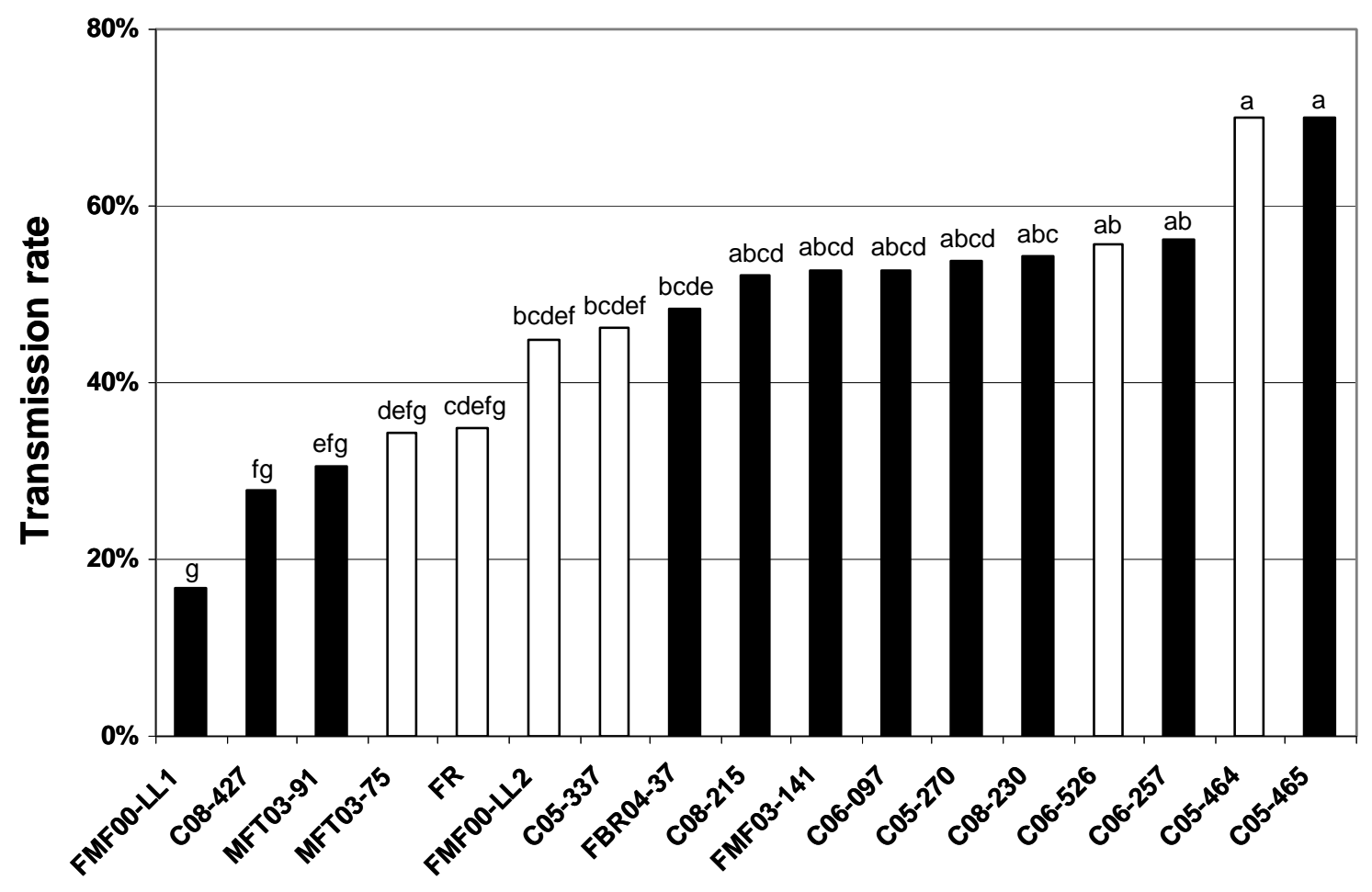

WMV isolates

Fig. 2. Transmission rates estimated for $17 \mathrm{WMV}$ isolates using infected zucchini squash 4 wk after inoculation as virus sources and single Myzus persicae placed on each of 30 melons at the cotyledonary stage and a total of 6 replicates. CL isolates are indicated with the white bars, EM isolates with the black bars, and isolates with a same letter over the bars are not significantly different. 


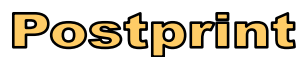

Version définitive du manuscrit publié dans / Final version of the manuscript published in : Virus Research, 2011, In press, DOI:10.1016/j.virusres.2011.05.004. The original publication is available at http://www.sciencedirect.com/science/article/pii/S0168170211001717
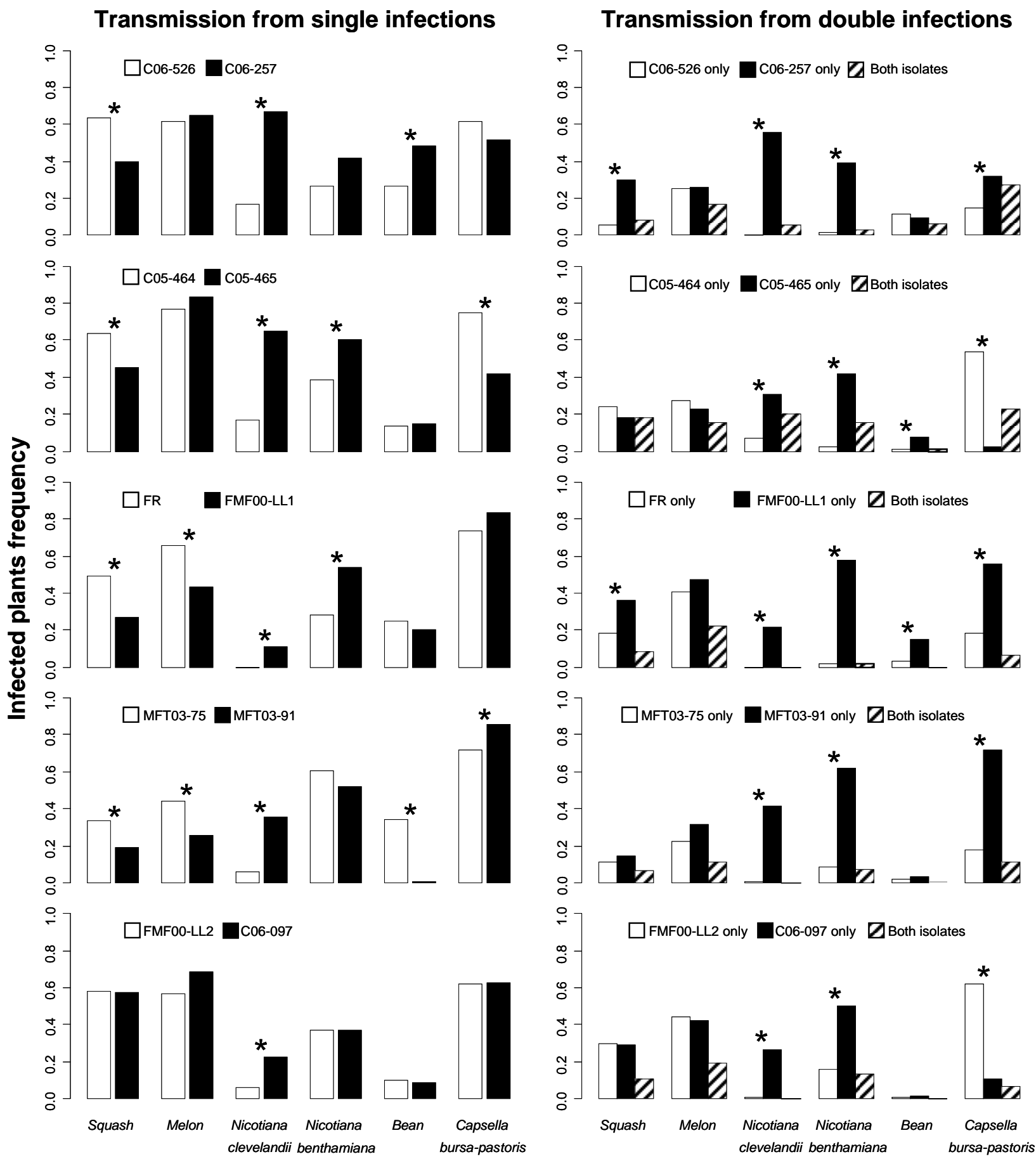

Fig. 3. Transmission rates of CL and EM WMV isolates from single (left) or double (right) infections shown as the infected plants frequency on scale of 0-1. CL isolates are indicated with the white bars, EM isolates with the black bars, and mixed (CL-EM) infection with the hatched bars.

* indicates significant differences at $p<0$. 